\title{
The Use of Educational Drama for Teaching the Arabic language and its Effect on the Development of Literacy Fluency and the Trend Towards Teamwork for Primary School Students
}

Hassan T. Sefen

Faculty of Education, Qena, South Valley University

\section{Abstract}

The research aimed to identify the effect of the use of educational drama in teaching the Arabic language on the development of reading fluency skills and the direction towards group work among primary school pupils. The study sample consisted of two experimental groups (33) pupils, and the other control (33) pupils from the fifth primary class In Sidi Abdel Rahim Joint Primary School in Qena Governorate, the study tools consisted of a test of reading fluency skills and a measure of the direction towards university work, and the results of the study resulted in a statistically significant difference between the average scores of students of the experimental and control groups in the application Dimension to test the fluency of literacy skills, as well as there is a statistically significant difference between the mean scores of students of the experimental and control groups in the application dimension to measure the trend towards collective action in favor of the experimental group, the study provided a set of recommendations proposed research.

Keywords: Educational Drama ; Arabic language ; Reading Fluency ; The Trend Towards Teamwork

Citation: Sefen., H.The Use of Educational Drama for Teaching the Arabic language and its Effect on the Development of Literacy Fluency and the Trend Towards Teamwork for Primary School Students, SVU-Journal of abstract 2020, 2 (1): pp1 (retrieved from the SVUInternational Journal Of Educational Sciences,2020, No 4)

Copyright: : Publisher South Valley University. This is an open access article distributed under the terms of the creative common attribution license, which permits unrestricted use, distribution and reproduction in any medium provided the original author and source are created. 